Article

\title{
Comparison of Selected Properties of Shellac Varnish for Restoration and Polyurethane Varnish for Reconstruction of Historical Artefacts
}

\author{
Kristýna Šimůnková, Miloš Pánek * and Aleš Zeidler \\ Department of Wood Products and Wood Constructions, Faculty of Forestry and Wood Sciences, \\ Czech University of Life Sciences Prague, Kamýcká 129, Prague 165 21, Czech Republic; \\ simunkovak@fld.czu.cz (K.Š.); zeidler@fld.czu.cz (A.Z.) \\ * Correspondence: panekmilos@fld.czu.cz; Tel.: +420-224-383-867
}

Received: 12 March 2018; Accepted: 21 March 2018; Published: 24 March 2018

\begin{abstract}
At present, many historical artefacts and furniture are only reconstructed and not restored. They are preserved in terms of material reparation, but their historical value decreases significantly. This work is focused on the comparison of the resistance of high-gloss polyurethane varnish with traditional shellac varnish. The varnishes were applied to oak wood and exposed to interior artificial accelerated ageing in Xenotest. Before and after ageing, cold liquid-resistance tests were performed on the tested specimens and gloss, colour, and adhesion were also evaluated. The structures of the surfaces were also analysed using a confocal laser scanning microscope. As expected, polyurethane varnish was much more durable than shellac varnish. Interestingly, shellac varnish was fairly resistant to water at the beginning, but this resistance was greatly reduced after artificial accelerated ageing. This illustrates the importance of sheltering the shellac treated artefacts in stable temperature-humidity conditions with the least possible effect of solar radiation.
\end{abstract}

Keywords: historical furniture; varnishes; shellac; durability; artificial ageing

\section{Introduction}

The restoration of damaged wooden artefacts requires observance of procedures and materials that were used for the production of originals during the relevant historical period [1]. It is used to preserve artefacts, traditional materials and craftsmanship, which are an integral part of cultural heritage. At present, many artefacts are only reconstructed and not restored [2,3]. This is due to the lower cost of renovation, easy accessibility, and often better features of modern materials (adhesives, coatings, etc.), faster process and in some cases, insufficient experience of the person carrying out the renovation. One positive aspect is the fact that the artefact is preserved in material terms; however, its historical value decreases significantly.

Before the introduction of synthetic paints, surface treatments of furniture, plastics or interior equipment were mainly done using oils, waxes, polychromes, paints, and transparent shellac varnishes [4].

Shellac is a raw material of natural origin that is obtained by collecting excrements of subtropical aphids (Kerria lacca L.) originating in China, India, Myanmar, and Thailand [5]. Its use is mostly in the pharmaceutical [6,7] and food industry [8]. In woodworking, in addition to surface treatment [9-11], it is also used for the production of composite materials [12], as an alternative method of enhancing the bio-resistance of wood [13] and for conservation of damaged wood [14]. Its greatest advantages are health and ecotoxicology harmlessness, relatively good resistance to humidity $[15,16]$, and the ability to form a continuous film with high gloss [5,17]. Its main disadvantages include low resistance 
to various chemicals [18], low colour stability due to UV radiation, and lower mechanical resistance to scratching $[5,10]$. When preparing the wood coating, it is first cleaned, dissolved in ethanol and then, via several repeated applications, grinding and polishing, the shellac varnish is applied to the wood surface, where it creates a high-gloss finishing that highlights the texture of wood. From timbers that are used today, the following tree species were used to produce historic furniture in Baroque, such as spruce (Picea abies Karst L.), fir (Abies spp.), pine (Pinus spp.) used for chest-making, and larch (Larix spp.). Primarily oak (Quercus spp.) and beech (Fagus sylvatica L.) were used to imitate valuable exotic woods from hardwoods $[3,19]$. Exotic species, such as European walnut (Juglans regia L.) and oak (Quercus spp.), were used for the production of historical luxury furniture (intarsia) [20]. These timbers were attractive due to their interesting structure and colour [21] and good durability against wood-destroying fungi, moulds, and wood-destroying insects [22].

The shellac varnish is not only a tool for restoration works, but it is also currently used to produce luxury interior furniture and replicas of historical pieces [19]. However, it is often replaced by a cheaper and easily-applicable substitute in the form of polyester or polyurethane varnishes, which, in combination with appropriate wood staining, provide a relatively faithful imitation $[3,23]$.

In literature, there are only few works dealing the properties of shellac varnishes of wood $[10,11,16,17,24,25]$. In the works of Gupta et al. [17] and Kumar et al. [16], the resistance of shellac varnish against the permeability of water vapours from the surrounding environment was investigated. In the works of Ghosh et al. [11] and Jankowska and Szczesna [10], the changes in gloss and colour were observed due to artificial accelerated ageing in a UV chamber or by sunlight. In the works of Weththimuni et al. [24] and Licchelli et al. [25], in addition to the traditional shellac varnish properties after UV exposure, the impact of modifications (nanoparticles or chemical modifications) on selected properties was investigated. The above-mentioned works did not examine oak as the underlying wood with its specific structure and content of tannins. The resistance of varnish to selected liquids according to EN 12720+A1 [26], which may be potentially altered due to the influence of air humidity and UV radiation, thereby resulting in ageing of the polymer structure of the shellac [27], was also not studied.

The aim of this study was to evaluate the selected properties of natural shellac varnish on oak wood, to determine their changes in the course of artificial ageing in Xenotest and to compare them to synthetic durable [28] high-gloss polyurethane coating used for reconstruction and replicas of historical artefacts. Another aim was to establish recommendations on how to avoid possible degradations and damages of shellac coating on historical artefacts based on the results.

\section{Material and Methods}

\subsection{Wood and Varnishes}

In order to test each coating, in this work eight test specimens of $430 \mathrm{~mm} \times 100 \mathrm{~mm} \times 16 \mathrm{~mm}$ $(L \times T \times R)$ oak wood (Quercus robur L.) from the Czech Republic with an average density of $\rho_{0}=698 \mathrm{~kg} / \mathrm{m}^{3}$ and a moisture content of $10 \% \pm 2 \%$ have been used. At the same time, non-coated reference samples were prepared from the same material (Figure 1a). All of the tested samples were sanded using sandpaper with a grit of 120 in a longitudinal direction.

Shellac varnish (SH) manufactured by Borma Wachs (Jesolo, Italy) had a low wax content that caused an orange shade after it was applied to wood (Figure 1b). It was applied within three days via multiple layering according to traditional techniques used in the past [19]. The thickness of the final layer was approximately $120 \mu \mathrm{m}$. The colour and gloss values before ageing were $L^{*}=46.51$ $(\mathrm{SD}=2.02) ; a^{*}=18.83(\mathrm{SD}=0.82) ; b^{*}=34.49(\mathrm{SD}=2.74)$; and gloss under $60^{\circ}$ was $77.05(\mathrm{SD}=4.71)$.

Polyurethane varnish (PUR) manufactured by the Sokrates company (Chlumec and Cidlinou, Czech Republic) is a single-component, water-soluble transparent coating (Figure 1c) with UV stabilizers (on the basis of benzotriazoles) and hydrophobizing components (on the basis of waxes). The first penetration was diluted by water to a 70\% concentration. Two layers of pure polyurethane 
coating were then applied after fine grinding. The thickness of the final layer was approximately $100 \mu \mathrm{m}$. The colours and gloss values before ageing were $L^{*}=60.76(\mathrm{SD}=2.18) ; a^{*}=7.12(\mathrm{SD}=0.52)$; $b^{*}=24.13(\mathrm{SD}=1.82)$; and gloss under $60^{\circ}$ was $71.32(\mathrm{SD}=5.60)$.

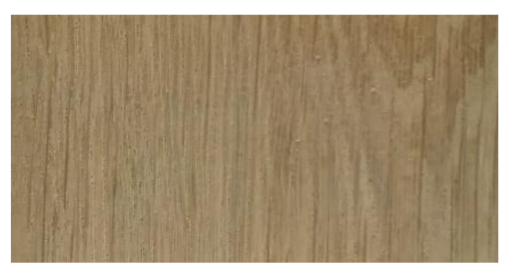

(a)

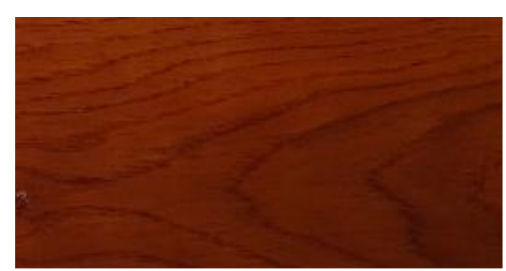

(b)

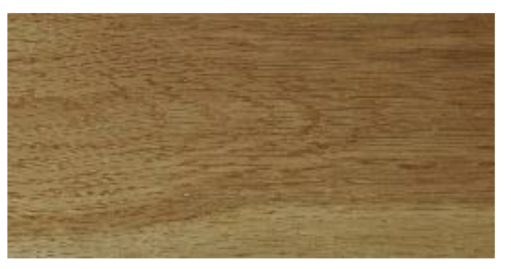

(c)

Figure 1. (a) Oak wood samples without varnish (REF); (b) with shellac varnish (SH); and (c) polyurethane varnish (PUR) before testing.

\subsection{Testing}

\subsubsection{Artificial Ageing}

Artificial ageing was carried out in Xenotest Q-Sun Xe-3 (Q-Lab, Cleveland, OH, USA) on the basis of modified EN 15187 [29] using a window glass filter (Window Glass-Q). The testing parameters are listed in Table 1.

Table 1. One cycle of artificial ageing in Xenotest according to modified EN ISO 16474-2 [30].

\begin{tabular}{|c|c|}
\hline Ageing in Xenotest One Cycle $=12 \mathrm{~h}$ & Functions \\
\hline 1st step & $\begin{array}{l}\text { Air temperature } 40{ }^{\circ} \mathrm{C} \text {; temperature at nlack panel } 55^{\circ} \mathrm{C} \text {; } \\
\text { water-spray (off), UV irradiance between } 300-400 \mathrm{~nm} \text { (TUV) } \\
20 \mathrm{~W} \cdot \mathrm{m}^{-2} \text {; relative air humidity } 40 \%\end{array}$ \\
\hline 2nd step & $\begin{array}{l}\text { Air temperature } 40^{\circ} \mathrm{C} \text {; temperature at nlack panel } 55^{\circ} \mathrm{C} \text {; } \\
\text { water-spray (off), UV irradiance between } 300-400 \mathrm{~nm} \text { (TUV) } \\
20 \mathrm{~W} \cdot \mathrm{m}^{-2} \text {; relative air humidity } 70 \%\end{array}$ \\
\hline
\end{tabular}

In order to intensify the artificial ageing, two steps with different air humidity (Table 1) were used in the xenon chamber set according to the modified EN ISO 16474-2 [30]. The tested properties of the samples were evaluated after 120 and $240 \mathrm{~h}$ of artificial accelerated ageing.

\subsubsection{Cold Liquids}

The test was carried out according to standard EN 12720+A1 [26]. We tested the resistance of varnishes against four selected liquids-Turkish coffee, black tea, red wine, and water. Cotton swabs filled with the cold liquids were placed under the Petri dishes for $24 \mathrm{~h}$. After removal, the surfaces were gently cleaned, dried at $T=20^{\circ} \mathrm{C}$, and a relative humidity of $60 \%$ and subsequently evaluated for changes in surface properties. Water tests were performed after $240 \mathrm{~h}$ of the artificial ageing in Xenotest (see Table 2).

On the coated test samples, the values of the colour coordinates [31] and gloss [32] were measured at the same locations before and after the tests. The destructive tests for adhesion tests [33] and pencil hardness of varnishes [34] were carried out before and after the ageing tests. The reference samples were only evaluated for colour and gloss changes after 120 and $240 \mathrm{~h}$ of ageing in Xenotest (Table 2). 
Table 2. Types and labelling of the test samples according to applied coatings and the type of the ageing (Xenotest and cold liquids).

\begin{tabular}{ccc}
\hline Samples & Testing & \multicolumn{1}{c}{ Measurements } \\
\hline SH-R, PUR-R, & References without ageing & adhesion, hardness \\
SH, PUR, REF & Ageing in Xenotest 120 and 240 h & Colour, gloss, adhesion, hardness changes \\
SH1, PUR1 & Against cold liquids-coffee & Colour, gloss, adhesion, hardness changes \\
SH2, PUR2 & Against cold liquids-tee & Colour, gloss, adhesion, hardness changes \\
SH3, PUR3 & Against cold liquids-red wine & Colour, gloss, adhesion, hardness changes \\
SH4, PUR4 & Against cold liquids-water & Colour, gloss, adhesion, hardness changes \\
SH5, PUR5 & 240 h in Xenotest, followed by & Colour, gloss, adhesion, hardness changes \\
& resistance against water & \\
\hline
\end{tabular}

\subsection{Measurements}

\subsubsection{Gloss Measurements}

The gloss was measured according to EN ISO 2813 [31] at an angle of 60. A MG268-F2 glossmeter (KSJ, Quanzhou, China) was used to measure gloss. A total of ten gloss measurements were performed for individual tested coatings after 120 and $240 \mathrm{~h}$ of artificial accelerated Xenotest ageing, and sixteen measurements after cold water resistance tests.

\subsubsection{Colour Analyses}

The colour parameters of the tested samples were measured before and after the artificial accelerated Xenotest ageing after 120 and $240 \mathrm{~h}$ and before and after cold water resistance tests using Spectrophotometer CM-600d (Konica Minolta, Osaka, Japan). The device was set to an observation angle of $10^{\circ}, d / 8$ geometry and D65 light source and the SCI method was also used. Ten measurements per each type of varnish treatment were carried out for each kind of test at the same location of the sample. Evaluations were done in CIE- $L^{*} a^{*} b^{*}$ colour space on the basis of $L^{*}, a^{*}$ and $b^{*}$ colour coordinates, where: $L^{*}$ is the lightness from 0 (black) to 100 (white), $a^{*}$ is the chromaticity coordinate + (red) or (green) and $b^{*}$ is the chromaticity coordinate + (yellow) or - (blue). The relative changes in $\operatorname{colour}\left(\Delta L^{*}\right.$, $\Delta a^{*}$, and $\left.\Delta b^{*}\right)$ between the weathered and the initial state were determined. The total colour difference $\Delta E^{*}$ (ASTM D2244-16 [31]) was subsequently calculated using the following Equation (1):

$$
\Delta E *=\sqrt{\Delta L *^{2}+\Delta a *^{2}+\Delta b *^{2}}
$$

\subsubsection{Adhesion of Varnishes}

A pull-off test was used and performed in accordance with ASTM D4541 [33]. For each type of the tested sample, five test rollers of $20 \mathrm{~mm}$ diameter were glued using an epoxy adhesive (UHU Plus_endfest, Bühl, Germany). The tests were carried out using Comtest OP 1 P 20 (Coming Plus, a.s., Prague, Czech Republic) and the tear strength in MPa was measured.

\subsubsection{Hardness of Varnishes}

The hardness of the tested varnishes was evaluated using the Wolff Wilborn pencil hardness test [34]. A TQC VF2378-322 device (TQC, Capelle aan den IJssel, Rotterdam, The Netherlands) was used with a load of $750 \mathrm{~g}$ and an angle of $30^{\circ}$ to the tested surface. Three measurements were performed for the each surface.

\subsubsection{Microscopic Analyses}

Microscopic structural changes in tested shellac and polyurethane varnishes were studied using confocal laser scanning microscope Lext Ols 4100 (Olympus, Tokyo, Japan) with 108-fold magnification. 


\subsubsection{Statistical Evaluation}

Statistical analyses were performed in MS Excel 2016 and Statistica 13.2 (StatSoft, Palo Alto, CA, USA) using mean values, standard deviations, whisker plots with mean values, and $95 \%$ two-sided confidence intervals, box and whiskers plots, and Tukey HSD test at $95 \%$ statistical significance.

\section{Results and Discussion}

The experimental tests confirmed the overall lower resistance of the natural shellac varnish compared to synthetic polyurethane used for oak wood. The resistance of the shellac coating to water was greatly reduced after the artificial accelerated ageing in Xenotest, based on the modified EN ISO 16474-2 [29]. Due to the rapid decline in moisture content during the artificial accelerated ageing cycle from $\varphi=70 \%$ to $\varphi=40 \%$, evaporation of water occurred from the underlying oak wood. Due to the relatively low permeability of shellac for vapours $[15,17]$ and changes in its structure due to photodegradation [27], its compactness was disrupted by the pressure of evaporating water (Figure 2). This significantly affected the evaluated properties after $240 \mathrm{~h}$ of artificial accelerated ageing in the Xenotest (see the next section, Figures 3 and 4).

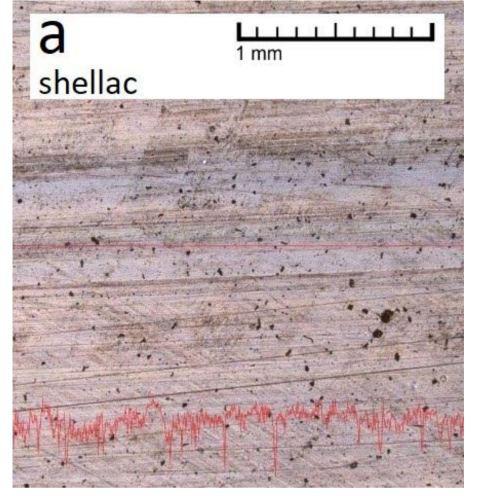

(a)

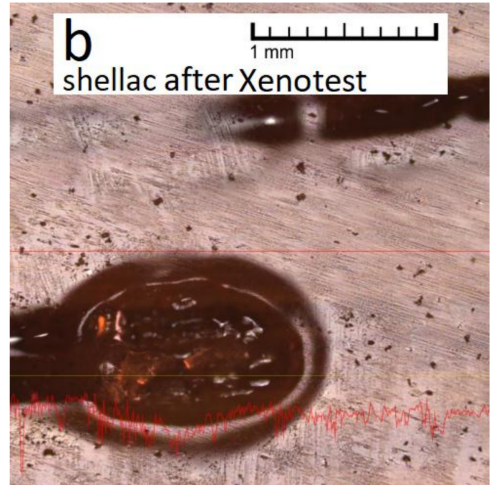

(b)

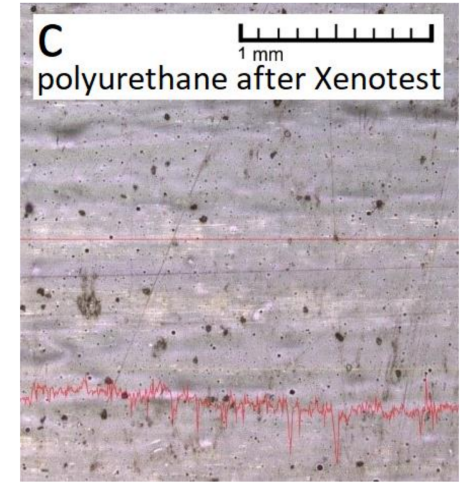

(c)

Figure 2. Changes of microscopic structure of shellac $(\mathbf{a}, \mathbf{b})$ and polyurethane (c) varnish after accelerated ageing in Xenotest. On the shellac varnish surfaces (a) creation of blisters was observed after artificial weathering in Xenotest (b). In contrast polyurethane varnish surfaces were not damaged (c).

\subsection{Colour Changes}

Colour changes were evaluated using the total change in colour $\Delta E^{*}$, change in light $\Delta L^{*}$ and change in parameters $\Delta a^{*}, \Delta b^{*}$, which, in the case of positive values, divert to red and yellow shades (Figure 3a-d). In the reference untreated oak, the decomposition of lignin [35] and extractives [36] by UV and VIS radiation resulted in a decrease of $L^{*}$ brightness and in the change in the shades to red and yellow colour in agreement with Oltean et al. [37] and Pandey [38]. In the case of polyurethane varnish, the initial $b^{*}$ (yellow shade) was increased after $120 \mathrm{~h}$ of artificial ageing, but later the $L^{*}$ rather increased after $240 \mathrm{~h}$ and less significant changes occurred in the case of the $a^{*}$ and $b^{*}$ values. As colour changes varied in comparison with untreated wood, there was a significant change in colour in the case of PU film itself due to UV radiation and moisture content fluctuations. In the case of shellac varnish, in the initial phase of the artificial ageing, a significant decrease of brightness (Figure 3b) and the transition to red and more pronounced yellow shades was confirmed in accordance with the works of Jankowska and Szczesna [10] and Weithithuni et al. [24]. After $240 \mathrm{~h}$ of artificial ageing, however, surface lightening ( $L^{*}$ increase and a significant decrease of $b^{*}$ values) occurred, resulting in a significant decrease in colour change (Figure 3), which corresponded approximately to the initial state. This could by caused by the synergistic effect of VIS and UV spectra in the Xenotest and the fluctuations in moisture content that resulted in the degradation of the shellac and the colour change 
of the orange shade we used (Figure 1). More distinct colour changes after the subsequent water effect on the surface after artificial ageing, compared to the surface before the ageing process, also support this hypothesis (Figure 4, SH4 versus SH5). The decrease of hydrophobicity of the shellac varnish surface after exposure to UV radiation was also observed in the study by Weththimuni et al. [24].

Significantly higher overall colour changes in shellac compared to polyurethane are demonstrated in Figure 3e,f. The results confirm the excellent resistance of synthetic polyurethane to ordinary used fluids [39]. On the contrary, shellac is quite susceptible to damage due to the inappropriate exposure stress [5,18].

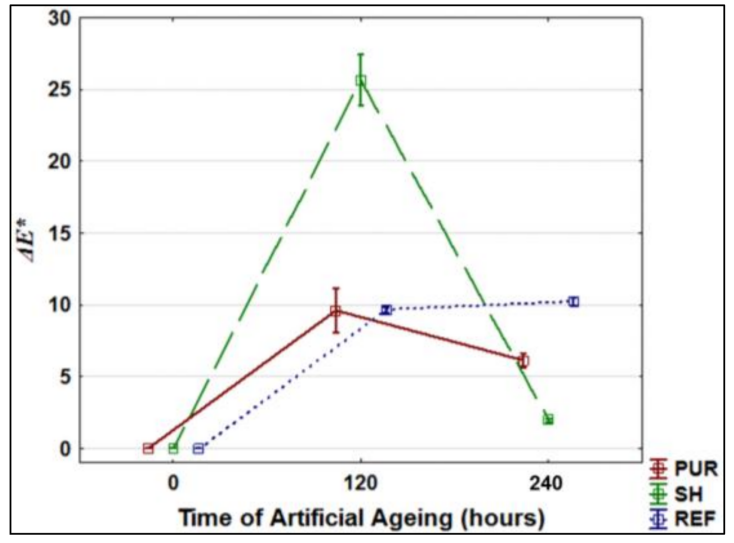

(a)

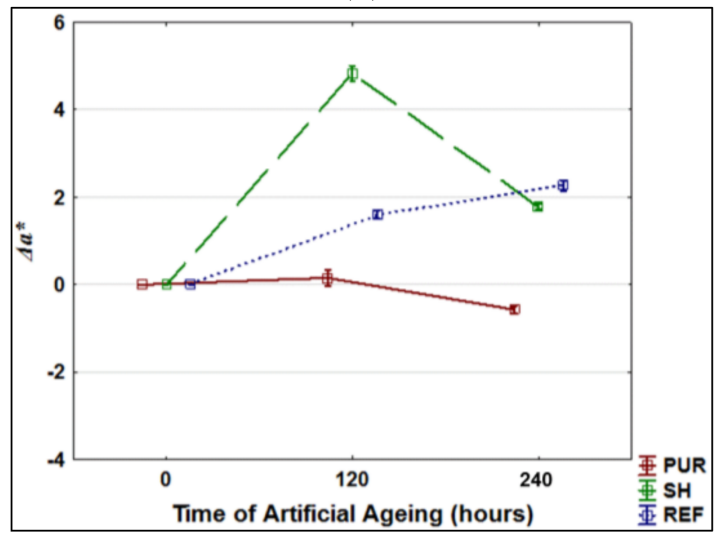

(c)

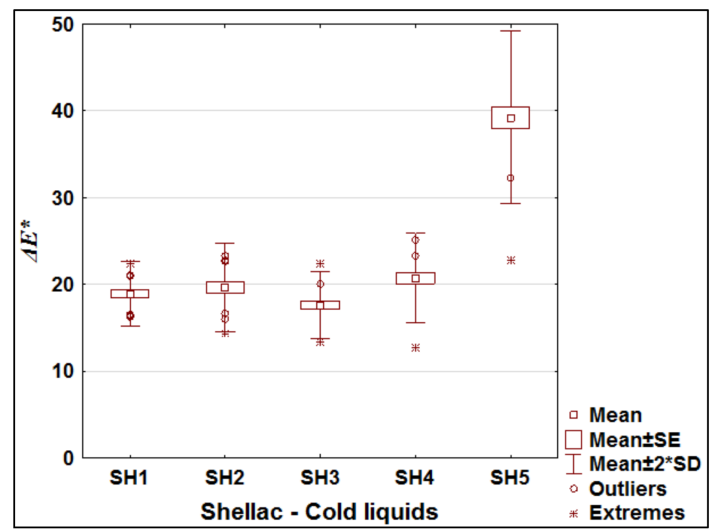

(e)

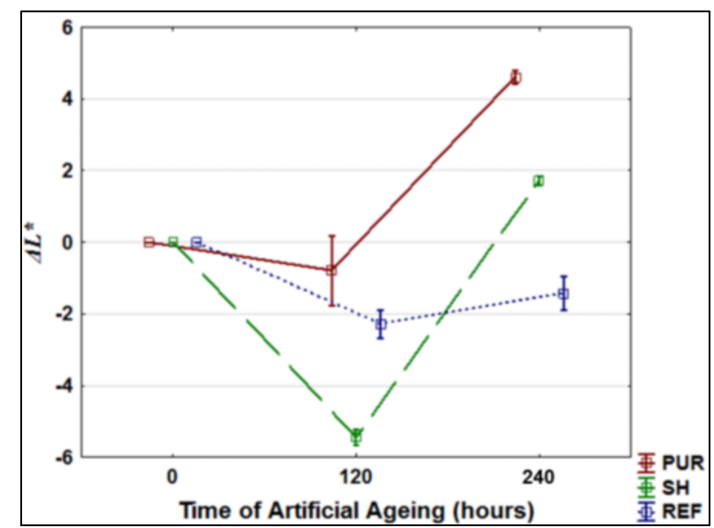

(b)

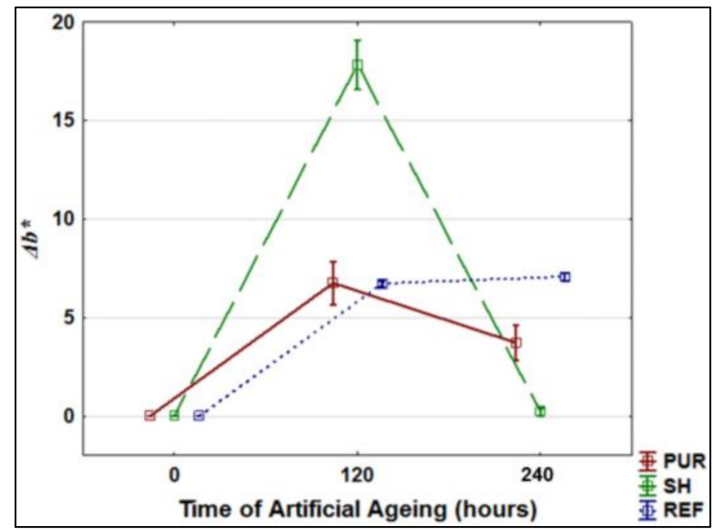

(d)

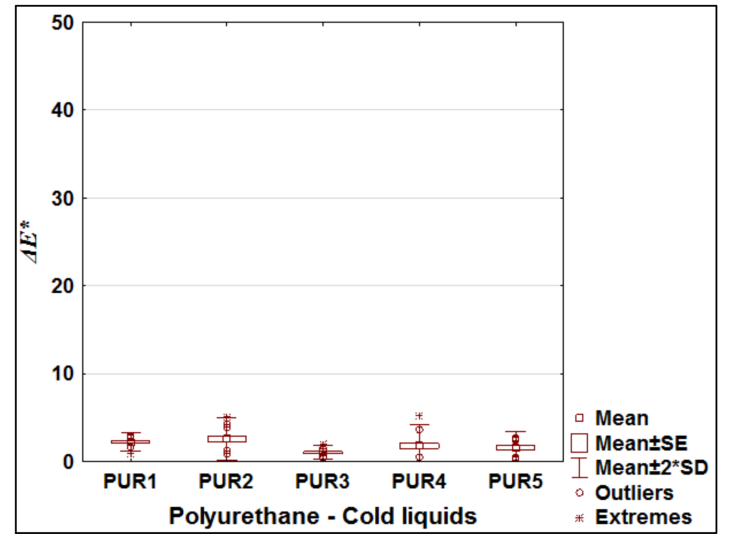

(f)

Figure 3. The $95 \%$ two-sided confidence intervals of colour changes in shellac (SH) and polyurethane (PUR) varnishes after artificial ageing (a-d); box and whiskers plots of colour changes after cold liquids tests $(\mathbf{e}, \mathbf{f})$. 
(a)

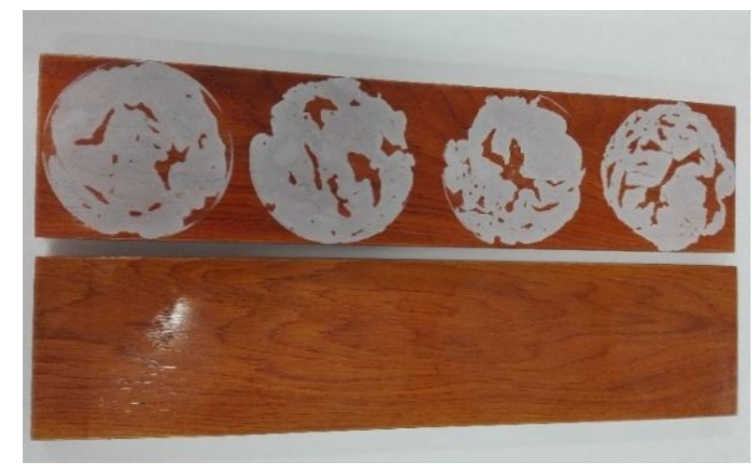

Figure 4. Colour changes in shellac after exposition to water (a) after artificial ageing; (b) before artificial ageing.

\subsection{Gloss Changes}

The gloss changes in the test surfaces were very small after the artificial accelerated ageing in the Xenotest (Figure 5). A slight decrease in the gloss of PU and untreated wood is in accordance with the work of Ghosh et al. [11]. A slight decrease in the gloss of shellac varnish (but with a relatively high variability of measured data) in this work was not confirmed in our research. The results confirm the ability of shellac to retain the high gloss for a long time, thereby improving the appearance of wooden surfaces in the interior.

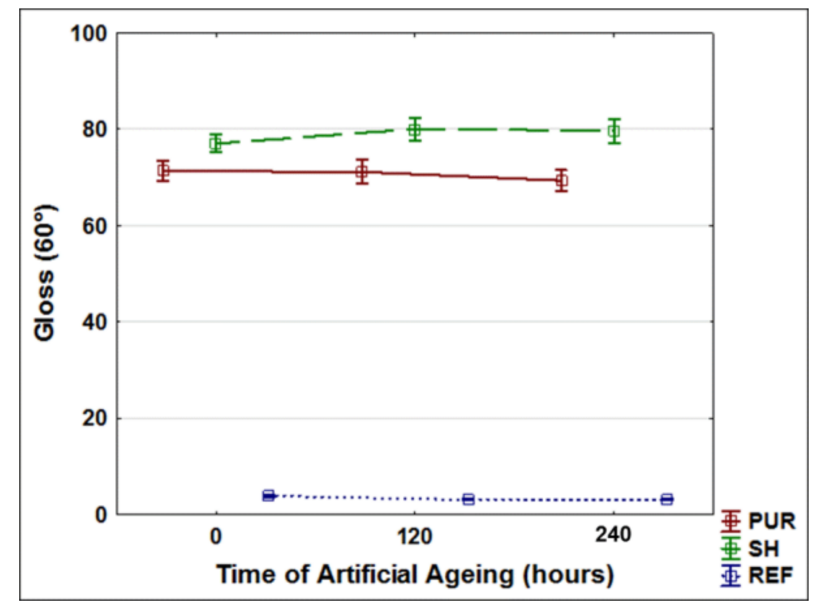

Figure 5. The 95\% two-sided confidence intervals of gloss changes in shellac ( $\mathrm{SH}$ ) and polyurethane (PUR) varnishes after artificial ageing in Xenotest.

However, significant changes in gloss (Figure 6a), mainly in the case of shellac varnish, were observed after application of the cold liquids [26]. After the exposure to water, the most pronounced decrease occurred after the artificial ageing in the Xenotest. This confirms the results for the colour changes (Figures 3 and 4 ) and for significantly reduced shellac resistance to water due to ageing and exposure to UV radiation and moisture content fluctuations. Greater changes in gloss were also caused by red wine, which degrades the shellac varnish due to ethanol $[5,25]$ more significantly than the other tested cold liquids. The polyurethane varnish showed good resistance [39] and only the effect of tea significantly reduced the gloss values (Figure 6b), likely due to tannin deposition which could not be removed before the measurement (see also slightly higher total change in colour PUR2 in Figure 3f). 


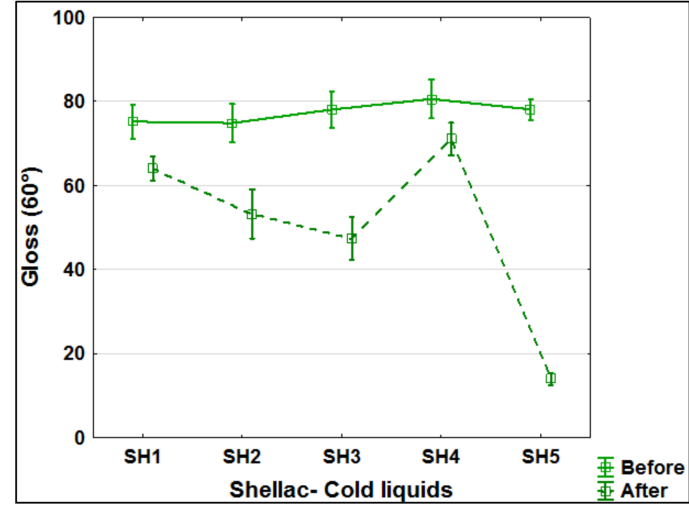

(a)

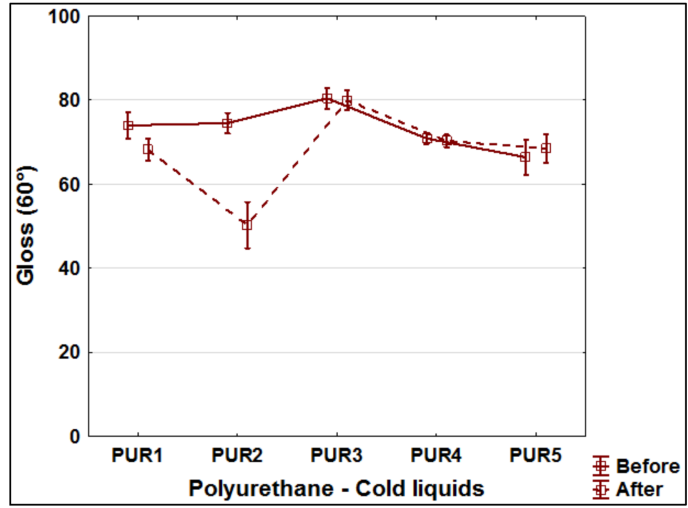

(b)

Figure 6. The 95\% two-sided confidence intervals of gloss changes in shellac ( $\mathrm{SH},(\mathbf{a}))$ and polyurethane (PUR, (b)) varnishes after cold liquid test.

\subsection{Adhesion and Hardness of Varnishes}

During the measurement of adhesion of varnishes, according to ASTM D4541 [33], using a pull-off adhesion tester, quite complicated tears in different layers of varnishes, wood, or their interfaces occurred. This was mainly due to the complicated morphological structure of oak [21] with large opened vessels that do not allow the uniform thickness of the coating film to be achieved. Therefore, the overall interpretation of the obtained results is difficult and the variability of the measured values is relatively high. Overall, shellac adhesion for oak wood was lower compared to polyurethane varnish (Figure 7). Good adhesion of polyurethane to wood was also reported by Carter [40]. The results in Figure 7 confirm that the kind of coating play the important role [41,42]. The lowest values were obtained for the shellac after $240 \mathrm{~h}$ of the artificial accelerated ageing (SH-240h in Figure 7) and after subsequent water testing (SH5 in Figure 7). These results confirm previous preliminary tests-especially colour changes (Figures 3 and 4 ) and lower resistance of shellac against UV-radiation [10] and water effect after UV ageing [24].

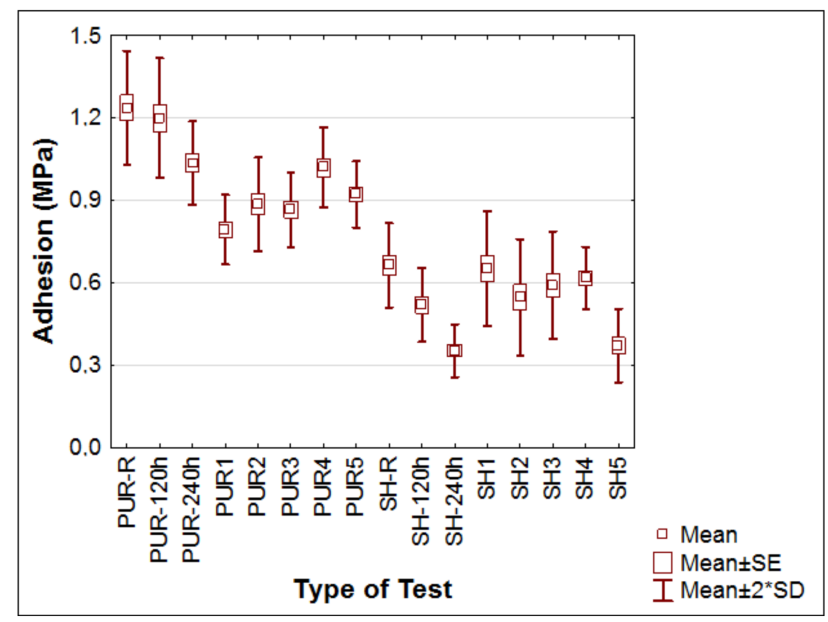

Figure 7. Box and whiskers plot of adhesion of varnishes before and after ageing and cold liquid tests.

Pencil hardness of varnishes is evaluated in Table 3 on the basis of EN ISO 15184 [34].

The tested polyurethane varnish had a low hardness (according to EN ISO 15184 [34]) that did not change even after the ageing and the cold liquid tests. The shellac coating had a low hardness at the beginning (Table 3), but it was increased during ageing in Xenotest by one degree. The same 
phenomenon was observed after the cold liquid tests. The impact of UV and VIS radiation on the change in the polymeric structure of shellac [24,27] and its mechanical properties [24] led to an increase in hardness of the coating film. This may, on the other hand, result in higher brittleness.

Table 3. Pencil hardness of varnishes before and after ageing and cold liquids tests.

\begin{tabular}{|c|c|c|c|c|c|c|c|c|}
\hline Varnish/Type of Test & $\mathbf{R}$ & $150 \mathrm{~h} \mathrm{UV}$ & $240 \mathrm{~h} \mathrm{UV}$ & 1 & 2 & 3 & 4 & 5 \\
\hline PUR & $3 \mathrm{~B}$ & $3 \mathrm{~B}$ & $3 B$ & $3 \mathrm{~B}$ & $3 B$ & $3 B$ & $3 B$ & $3 B$ \\
\hline $\mathrm{SH}$ & $3 \mathrm{~B}(2 \mathrm{~B})$ & $3 \mathrm{~B}(2 \mathrm{~B})$ & $2 B$ & $\begin{array}{c}2 \mathrm{~B} \\
(3 \mathrm{~B})\end{array}$ & $2 B$ & $2 B$ & $2 \mathrm{~B}$ & $2 \mathrm{~B}$ \\
\hline
\end{tabular}

Note: 3B (2B) means that most measurements were 3B but also 2B exist in some cases.

It is clear from the overall evaluation (Figures 3-7, Tables 3 and 4) that compared to a durable polyurethane varnish, the shellac varnish has lower resistance to UV radiation in combination with air humidity fluctuations [28]. This fact was also confirmed by other authors [10,11,17]. Similarly, it is less resistant to cold liquids used in households (Figures 3, 6 and 7). Only the hardness of shellac was higher and slightly increased after exposure to UV radiation and cold liquids (Table 3), but this may indicate an increase in its brittleness. An interesting finding was the significant deterioration of resistance against water (Figures 3 and 4, Table 4 ) after accelerated artificial ageing with simultaneous fluctuations in air humidity and UV exposure. It is necessary to take into account this phenomenon and, if possible, to reduce the impact of air humidity fluctuations and the effects of UV radiation that are causing degradation and visual changes [10,24], and even changes in chemical polymer structures [5,27]. These results must be followed even during the restoration and subsequent preservation of historical artefacts. The shellac coating confirmed its ability to maintain high gloss [11] even after UV exposure, which is one of its advantages [5]. Another important advantage is its health harmlessness [6,8] and renewability as material. A possible way to improve its properties for the formation of varnishes is modification by various methods $[24,25,43]$. These processes can contribute to wider utilization of shellac coatings even for the production of contemporary interior furniture.

Table 4. Tukey HSD test of statistical significance of values $\Delta E^{*}$, gloss and adhesion for shellac and polyurethane varnishes before and after testing and between these two kinds of varnishes.

\begin{tabular}{cccccccccc}
\hline \multirow{2}{*}{ Type of Test } & \multicolumn{3}{c}{ Shellac (SH) } & \multicolumn{3}{c}{ Polyurethane (PUR) } & \multicolumn{3}{c}{ Between SH and PUR } \\
\cline { 2 - 10 } & $\boldsymbol{\Delta} \boldsymbol{E}^{*}$ & Gloss & Adh. & $\boldsymbol{\Delta} \boldsymbol{E}^{*}$ & Gloss & Adh. & $\boldsymbol{\Delta} \boldsymbol{E}^{*}$ & Gloss & Adh. \\
\hline R-without & - & - & - & - & - & - & - & $p<0.05$ & $p<0.05$ \\
UV-120 h & - & $p>0.05$ & $p>0.05$ & - & $p>0.05$ & $p>0.05$ & $p<0.05$ & $p<0.05$ & $p<0.05$ \\
UV-240 h & $p<0.05$ & $p>0.05$ & $p<0.05$ & $p>0.05$ & $p>0.05$ & $p<0.05$ & $p<0.05$ & $p<0.05$ & $p<0.05$ \\
1-coffee & $p>0.05$ & $p<0.05$ & $p>0.05$ & $p>0.05$ & $p>0.05$ & $p<0.05$ & $p<0.05$ & $p>0.05$ & $p>0.05$ \\
2-tea & $p>0.05$ & $p<0.05$ & $p>0.05$ & $p>0.05$ & $p<0.05$ & $p<0.05$ & $p<0.05$ & $p>0.05$ & $p<0.05$ \\
3-wine & $p<0.05$ & $p<0.05$ & $p>0.05$ & $p>0.05$ & $p<0.05$ & $p<0.05$ & $p<0.05$ & $p<0.05$ & $p<0.05$ \\
4-water & - & $p>0.05$ & $p>0.05$ & - & $p>0.05$ & $p<0.05$ & $p<0.05$ & $p>0.05$ & $p<0.05$ \\
5-UV + water & $p<0.05$ & $p<0.05$ & $p<0.05$ & $p>0.05$ & $p>0.05$ & $p<0.05$ & $p<0.05$ & $p<0.05$ & $p<0.05$ \\
\hline Note: The effect of cold liquids (1-5) inside group (SH or PUR) are for $\Delta E^{*}$ compared with cold water; Accelerated \\
ageing inside group (SH or PUR) are for $\Delta E^{*}$ compared with 120 hof ageing.
\end{tabular}

\section{Conclusions}

The shellac and polyurethane varnishes we used for oak wood were exposed to accelerated artificial ageing in the Xenotest with simultaneous exposure to UV radiation and fluctuations in air humidity. Tests of resistance to selected cold liquids were also performed and the effects of water were investigated after artificial accelerated ageing. Subsequently, changes in colour, gloss, adhesion and hardness of the varnishes and evaluation of visual and microscopic changes by CLSM were tested.

The polyurethane varnish was expected to be much more resistant and durable than shellac. Only the shellac hardness was higher and it even slightly increased after exposure to UV radiation and 
cold liquids. This may, however, indicate an increase in its fragility. An interesting finding was the markedly-reduced resistance of the shellac varnish to water after artificial accelerated ageing, although it resisted water relatively well before ageing. This illustrates the importance of keeping the treated artefacts and furniture in stable temperature-humidity conditions with as reduced an influence by sunlight as possible.

Acknowledgments: This work was supported by grant "Advanced research supporting the forestry and wood-processing sector's adaptation to global change and the 4th industrial revolution", No. CZ.02.1.01/ 0.0/0.0/16_019/0000803 financed by OP RDE.

Author Contributions: Kristýna Šimůnková designed and performed the experiments, analyzed the data and co-wrote paper; Miloš Pánek conceived, designed the experiments, analyzed the data and co-wrote the paper; Aleš Zeidler co-wrote the paper.

Conflicts of Interest: The authors declare no conflict of interest.

\section{References}

1. Rivers, S.; Umney, N. Conservation of Furniture; Routledge: Oxford, UK, 2007; p. 840, ISBN 9781136415364.

2. Brandi, C. Teoria del Restauro; Piccola Biblioteca Einaudi Ns; Tichá Byzanc: Kutná Hora, Czech Republic, 2000; p. 154, ISBN 9788806155650. (In Czech)

3. Losos, L. Historický Nábytek: Konstrukce, Údržba, Restaurování, 1st ed.; Grada: Praha, Czech Republic, 2013; p. 266, ISBN 978-80-247-3546-7. (In Czech)

4. Pelosi, C.; Calienno, L.; Fodaro, D.; Borrelli, E.; Rubino, A.R.; Sforzini, L.; Monaco, A.L. An integrated approach to the conservation of a wooden sculpture representing Saint Joseph by the workshop of Ignaz Günther (1727-1775): Analysis, laser cleaning and 3D documentation. J. Cult. Herit. 2016, 17, 114-122. [CrossRef]

5. Sharma, S.K.; Shukla, S.K.; Vaid, D.N. Shellac-Structure, Characteristics \& Modification. Def. Sci. J. 1983, 33, 261-271. [CrossRef]

6. Limmatvapirat, S.; Panchapornpon, D.; Limmatvapirat, C.; Nunthanid, J.; Luangtana-Anan, M.; Puttipipatkhachorn, S. Formation of shellac succinate having improved enteric film properties through dry media reaction. Eur. J. Pharm. Biopharm. 2008, 70, 335-344. [CrossRef] [PubMed]

7. Pearnchob, N.; Siepmann, J.; Bodmeier, R. Pharmaceutical applications of shellac: Moisture-protective and taste-masking coatings and extended-release matrix tablets. Drug Dev. Ind. Pharm. 2003, 29, 925-938. [CrossRef] [PubMed]

8. Limmatvapirat, S.; Nunthanid, J.; Puttipipatkhachorn, S.; Luangtana-anan, M. Effect of alkali treatment on properties of native shellac and stability of hydrolyzed shellac. Pharm. Dev. Technol. 2005, 10, 41-46. [CrossRef] [PubMed]

9. Minato, K.; Akiyama, T.; Yasuda, R.; Yano, H. Dependence of vibrational properties of wood on varnishing during its drying process in violin manufacturing. Holzforsch. Int. J. Biol. Chem. Phys. Technol. Wood 1995, 49, 222-226. [CrossRef]

10. Jankowska, A.; Szczesna, M. The study of colour changes of chosen species of wood from Southeast Asia caused by transparent coatings and exposure to sunlight. Drewno 2011, 54, 51-59.

11. Ghosh, M.; Gupta, S.; Kumar, V.S.K. Studies on the loss of gloss of shellac and polyurethane finishes exposed to UV. Maderas Cienc. Tecnol. 2015, 17, 39-44. [CrossRef]

12. Obradovic, J.; Petibon, F.; Fardim, P. Preparation and Characterisation of Cellulose-Shellac Biocomposites. BioResources 2017, 12, 1943-1959. [CrossRef]

13. Remadevi, O.K.; Siddiqui, M.Z.; Nagaveni, H.C.; Rao, M.V.; Shiny, K.S.; Ramani, R. Efficacy of shellac-based varnishes for protection of wood against termite, borer and fungal attack. J. Indian Acad. Wood Sci. 2015, 12, 9-14. [CrossRef]

14. Reinprecht, L. Possibilities for improvement of moisture and strength properties of decayed spruce wood with natural resins. Wood Res. 2011, 56, 285-296.

15. Hagenmaier, R.D.; Shaw, P.E. Permeability of Shellac Coatings to Gases and Water Vapor. J. Agric. Food Chem. 1991, 39, 825-829. [CrossRef] 
16. Kishan Kumar, V.S.; Upadhyay, K.K.; Gupta, S. Studies on moisture resistance of a traditional and a commercial finish on mango wood at elevated temperature and high relative humidity. J. Indian Acad. Wood Sci. 2009, 6, 36-44.

17. Gupta, S.; John, A.; Kumar, V.S. Studies on effect of coat thickness on the moisture uptake by a hardwood substrate. Maderas Cienc. Tecnol. 2016, 18, 443-456. [CrossRef]

18. Goswami, D.N.; Prasad, N.; Baboo, B.; Kumar, K.K.; Ansari, M.F. Degradation of lac with storage and a simple method to check the same. Pigment Resin Technol. 2009, 38, 211-217. [CrossRef]

19. Cook, W. The Complete Guide to Repairing \& Restoring Furniture; Southwater: Leicester, UK, 2015; p. 256, ISBN1 10 1780191448, ISBN2 13 978-1780191447.

20. Lyons, R.A. Restoring Antique Furniture: A Complete Guide; Dover Publications: New York, NY, USA, 2000; p. 144, ISBN1 10 0486409546, ISBN2 13 978-0486409542.

21. Wagenführ, R. Dřevo-Obrazový Lexikon; GRADA Publishing: Praha, Czech Republic, 2002; p. 348, ISBN 80-247-0346-7.

22. British Standards Institution (BSI). EN 350:2016 Durability of Wood and Wood-Based Products-Testing and Classification of the Durability to Biological Agents of Wood and Wood-Based Materials; European Committee for Standardization: Brussels, Belgium, 2016.

23. Miles, H. Meubels Restaureren; Rebo Productions: Noordwijkerhout, The Netherlands, 2002; p. 80, ISBN 903661418X, 9789036614184.

24. Weththimuni, M.L.; Capsoni, D.; Malagodi, M.; Milanese, C.; Licchelli, M. Shellac/nanoparticles dispersions as protective materials for wood. Appl. Phys. A 2016, 122, 1058. [CrossRef]

25. Licchelli, M.; Malagodi, M.; Somaini, M.; Weththimuni, M.; Zanchi, C. Surface treatments of wood by chemically modified shellac. Surf. Eng. 2013, 29, 121-127. [CrossRef]

26. The National Standards Authority of Ireland (NSAI). EN 12720+A1:2013—Furniture-Assessment of Surface Resistance to Cold Liquids; European Committee for Standardization: Brussels, Belgium, 2013.

27. Coelho, C.; Nanabala, R.; Ménager, M.; Commereuc, S.; Verney, V. Molecular changes during natural biopolymer ageing-The case of shellac. Polym. Degrad. Stab. 2012, 97, 936-940. [CrossRef]

28. Scrinzi, E.; Rossi, S.; Deflorian, F.; Zanella, C. Evaluation of aesthetic durability of waterborne polyurethane coatings applied on wood for interior applications. Prog. Org. Coat. 2011, 72, 81-87. [CrossRef]

29. EN 15187:2006 Furniture-Assessment of the Effect of Light Exposure; European Committee for Standardization: Brussels, Belgium, 2006.

30. EN ISO 16474-2:2014_Paints and Varnishes-Methods of Exposure to Laboratory Light Sources_Part 2: Xenon-Arc Lamps; European Committee for Standardization: Brussels, Belgium, 2014.

31. D2244-16:2016 — Standard Practice for Calculation of Color Tolerances and Color Differences from Instrumentally Measured Color Coordinates; ASTM International: West Conshohocken, PA, USA, 2016.

32. EN ISO 2813:2015-Paints and Varnishes-Determination of Gloss Value at $20^{\circ}, 60^{\circ}$ and $85^{\circ}$; European Committee for Standardization: Brussels, Belgium, 2015.

33. D4541-02:2002 Standard Test Method for Pull-off Strength of Coatings Using Portable Adhesion Testers; ASTM International: West Conshohocken, PA, USA, 2002.

34. EN ISO 15184:2013 — Paints and Varnishes_Determination of Film Hardness by Pencil Test; European Committee for Standardization: Brussels, Belgium, 2013.

35. Teacă, C.A.; Roşu, D.; Bodîrlău, R.; Roşu, L. Structural changes in wood under artificial UV light irradiation determined by FTIR Spectroscopy and color measurements-A brief review. BioResources 2013, 8, 1478-1507. [CrossRef]

36. Pastore, T.C.M.; Santos, K.O.; Rubim, J.C. A spectrocolorimetric study on the effect of ultraviolet irradiation of four tropical hardwoods. Bioresour. Technol. 2004, 93, 37-42. [CrossRef] [PubMed]

37. Oltean, L.; Teischinger, A.; Hansmann, C. Wood surface discolouration due to simulated indoor sunlight exposure. Holz Roh Werkst. 2008, 66, 51-56. [CrossRef]

38. Pandey, K.K. Study of the effect of photo-irradiation on the surface chemistry of wood. Polym. Degrad. Stab. 2005, 90, 9-20. [CrossRef]

39. Bomba, J.; Ježek, J.; Hýsek, Š.; Sikora, A.; Stoláriková, R.; Palacká, A.; Berková, M.; Kolbabová, T. Polyurethane coatings on hardwood and softwood surfaces: Their resistance to household liquids as an educational case study. Bioresources 2017, 12, 5867-5877. [CrossRef]

40. Carter, N. Scavenge moisture and cut pinholes in a trice. Eur. Coat. J. 2012, 6, 18-21. 
41. Vitosyto, J.; Ukvalbergieno, K.; Keturakis, G. The effects of surface roughness on adhesion strength of coated ash (Fraxinus excelsior L.) and Birch (Betula L.) wood. Mater. Sci. 2012, 18, 347-351. [CrossRef]

42. Ozdemir, T.; Hiziroglu, S. Influence of surface roughness and species on bond strength between the wood and the finish. For. Prod. J. 2009, 59, 90-94.

43. Otto, J.T.; Trumbo, D.L. A Shellac derivative in thermoset coatings. J. Coat. Technol. Res. 2010, 7, $525-527$. [CrossRef] 